\title{
Alterações nos parâmetros hematológicos de Gallus gallus domesticus experimentalmente infectados por Borrelia anserina ${ }^{1}$
}

\author{
Raquel S. Lisbôa ${ }^{2^{*}}$, Daniel S. Guedes Júnior², Fábio J.M. Silva², Nathalie C. \\ Cunha $^{2}$, Carlos H. Machado ${ }^{3}$ e Adivaldo H. Fonseca ${ }^{4}$
}

\begin{abstract}
Lisbôa R.S., Guedes Júnior D.S., Silva F.J.M., Cunha N.C., Machado C.H. \& Fonseca A.H. 2008. [Alterations in hematological parameters of Gallus gallus domesticus experimentally infected with Borrelia anserina.] Alterações nos parâmetros hematológicos de Gallus gallus domesticus experimentalmente infectados por Borrelia anserina. Pesquisa Veterinária Brasileira 28(10):527-532. Curso de PósGraduação em Ciências Veterinárias, Universidade Federal Rural do Rio de Janeiro, Seropédica, RJ 23890-000, Brazil. E-mail: raquellisboa@ufrrj.br

Avian spirochaetosis is a cosmopolite acute septicemic disease of many avian species, caused by Borrelia anserina Sakharoff, 1891. The present study assesses the estimate of the hematological alterations of Gallus gallus domesticus experimentally infected with $B$. anserina by vector Argas (Persicargas) miniatus. Twenty-seven fowls of the species G. g. domesticus, 67 days old, were randomly allocated into three groups composed by nine animals each. One group was exposed to $B$. anserina infected ticks (Group 1), other one to ticks free of this agent (Group 2), and another group not exposed to ticks (Group 3). Blood smears of the fowls were taken daily, since the first day the fowls were exposed to the ticks, up to the 25th day after exposure (DAE). Blood samples were collected three days before exposure, and three, eight and $18 \mathrm{DAE}$, for hematologic tests. The examination of Group 1 smears revealed large number of spirochaetes. Group 2 and 3 blood smears were negative during the whole period under exam. In agreement with the hematological evaluation results, the fowls exposed to infected ticks showed a normocytic normochromic anemia in eight DAE, leucocytosis with heterophilia and monocytosis concomitant with the spirochaetemia. We concluded that $B$. anserina infection determined on fowls of Group 1 hematological alterations compatible with bacterial infection of moderate gravity, developing to self-cure, in the experimental conditions established in this study.
\end{abstract}

INDEX TERMS: Borrelia anserina, Argas (Persicargas) miniatus, avian hematology, domestic fowls, avian spirochaetosis.

RESUMO.- Borreliose aviária é uma doença septicêmica aguda, cosmopolita, que acomete diferentes espécies aviárias, sendo causada por Borrelia anserina Sakharoff,

\footnotetext{
${ }^{1}$ Recebido em 22 de abril de 2008.

Aceito para publicação em 6 de junho de 2008.

Parte da Dissertação de Mestrado apresentada ao Curso de PósGraduação em Ciências Veterinárias (CPGCV), Universidade Federal Rural do Rio de Janeiro (UFRRJ).

2 Pós-Graduandos, CPGCV, UFRRJ, Seropédica, RJ 23890-000, Brasil. *Autor para correspondência: raquellisboa@ufrrj.br

${ }^{3}$ Departamento de Medicina e Cirurgia Veterinária, Instituto de Veterinária (IV), UFRRJ, Seropédica, RJ.

${ }^{4}$ Departamento de Epidemiologia e Saúde Pública, IV, UFRRJ, Seropédica, RJ.
}

1891. O objetivo do presente trabalho foi avaliar as alterações hematológicas em Gallus gallus domesticus experimentalmente infectados por $B$. anserina via vetor Argas (Persicargas) miniatus. Um total de 27 aves da espécie G. g. domesticus com 67 dias de vida, foram divididas em três grupos inteiramente casualizados contendo nove animais cada. Um grupo foi exposto a carrapatos infectados por $B$. anserina (Grupo 1); outro a carrapatos livres deste agente (Grupo 2); além de um grupo não exposto aos carrapatos (Grupo 3). Realizaram-se esfregaços sangüíneos diariamente, a partir do primeiro dia de exposição ao vetor, até o $25^{\circ}$ dia pós-exposição (DPE). Amostras de sangue foram coletadas 3 dias antes da exposição aos carrapatos, e 3, 8 e 18 dias pós-exposição (DPE), para a 
realização dos hemogramas. O exame dos esfregaços das aves do Grupo 1 revelou grande número de espiroquetas. Os esfregaços sangüíneos dos Grupos 2 e 3 mantiveram-se negativos durante todo o período experimental. De acordo com os resultados das avaliações hematológicas, as aves do Grupo 1 apresentaram um quadro de anemia normocítica normocrômica em oito DPE, além de leucocitose com heterofilia e monocitose que cursaram paralelamente ao período de espiroquetemia. Concluiuse que a infecção por $B$. anserina determinou nas aves do Grupo 1 alterações hematológicas compatíveis com uma infecção bacteriana de moderada gravidade, evoluindo para auto-cura, nas condições experimentais estabelecidas neste trabalho.

TERMOS DE INDEXAÇÃO: Borrelia anserina, Argas (Persicargas) miniatus, hematologia aviária, galinhas domésticas, espiroquetose aviária.

\section{INTRODUÇÃO}

Os hemoparasitos têm sido foco de diversos estudos em aves em diferentes países, o que se deve principalmente aos prejuízos econômicos por eles causados, além da importância do conhecimento das interações vetoresagentes etiológicos-hospedeiros. A borreliose aviária é uma doença de importância econômica para produção de aves, particularmente no sistema orgânico, por causar morbidade e alta mortalidade nos animais jovens.

Borrelia anserina Sakharoff, 1891 é o agente etiológico da borreliose aviária, uma doença septicêmica aguda que acomete diversas espécies de aves (Garg \& Gautam 1971). Os vetores são carrapatos do gênero Argas (DaMassa \& Adler 1979). Este espiroquetídeo foi descrito por Sakharoff (1891) que estudava septicemia em gansos no Caucasus. Marchoux \& Salimbeni (1903) foram os primeiros a relatar no Brasil, um surto natural em galinhas.

A enfermidade se manifesta por hipertermia e polidipsia inicial, sonolência, inapetência, diarréia verde-escura, evoluindo para cianose com hipotermia, podendo ocorrer transtornos paralíticos e morte. Diversos autores relataram a ocorrência de anemia nas aves infectadas por $B$. anserina (Hutyra et al. 1947, Shommein \& Khogali 1974, Bandopadhyay \& Vegad 1983). Porém, não há estudo dos parâmetros hematológicos das aves acompanhando a evolução da infecção, quando transmitida pelo seu vetor natural Argas (Persicargas) miniatus.

O objetivo do presente trabalho foi avaliar as alterações hematológicas em Gallus gallus domesticus infectados experimentalmente por $B$. anserina via vetor $A$. miniatus.

\section{MATERIAL E MÉTODOS}

A cepa de Borrelia anserina utilizada foi isolada a partir de Argas miniatus naturalmente infectados coletados de um pequeno grupo de galinhas da área rural do município de Pedro Leopoldo, estado de Minas Gerais, Brasil. Esta cepa, identificada geneticamente como B. anserina e chamada de cepa PL (Ataliba et al. 2007), foi mantida em nitrogênio líquido (-196C), criopreservada em soro de galinha infectado experimentalmente utilizando-se DMSO a 10\% como criopreservante (Labruna et al. 1999), no Laboratório de Doenças Parasitárias do Departamento de Epidemiologia e Saúde Pública, Instituto de Veterinária, Universidade Federal Rural do Rio de Janeiro (UFRRJ)/Projeto Sanidade Animal - Embrapa.

Foram utilizados carrapatos identificados como da espécie A. miniatus Koch, 1844 (Magalhães 1979), provenientes de criações rústicas de Gallus gallus domesticus, no município de Três Rios, RJ e no bairro de Santa Cruz, RJ, mantidos em estufa do tipo B.O.D. em temperatura de $27 \pm 1^{\circ} \mathrm{O} \mathrm{C}$ e umidade relativa de $80 \%$.

Para a obtenção dos carrapatos infectados, foi utilizada uma ave adulta que apresentou inicialmente, esfregaço sanguíneo negativo para presença de hemoparasitos. Posteriormente esta ave foi imunossuprimida por meio de administração via intramuscular, em dose única, de $30 \mathrm{mg} / \mathrm{kg}$ de acetato de metilprednisolona (Depo, Medrol ${ }^{\circledR}$ ) (Souza 1998). No dia seguinte esta ave recebeu o inóculo de $0,5 \mathrm{ml}$ de soro infectado, já submetido a uma passagem. Este soro quando observado em microscopia de campo escuro apresentou "++" de viabilidade de acordo com a classificação de Dhawedkar \& Dhanesar (1983). No quarto dia após a inoculação, a ave apresentou pico de espiroquetemia com incontáveis espiroquetas em 50 campos observados, os carrapatos foram então colocados para se alimentar até completo ingurgitamento. O líquido coxal destes carrapatos foi analisado através de microscopia de campo escuro, tendo sido detectada a presença de espiroquetas.

Foram utilizadas 27 aves da espécie G. g. domesticus, linhagem comercial "Isa Brown" para postura, adquiridas no comércio local. As aves foram mantidas dentro de gaiolas suspensas, dispostas homogêneamente em ambiente telado e ventilado em um galpão; sendo alimentadas com água ad libitum e ração elaborada com suplemento mineral-vitamínico isento de coccidiostático e sem promotor de crescimento.

As aves foram divididas em três grupos inteiramente casualizados contendo nove animais cada, sendo o Grupo 3, o controle. As aves dos Grupos 1 e 2 foram expostas a $A$. miniatus infectados com $B$. anserina e a $A$ miniatus livres de $B$. anserina, respectivamente. Dois casais de carrapatos foram colocados para se alimentarem na face interna das asas até ingurgitamento completo em cada ave. O grupo controle não foi exposto aos carrapatos.

Realizaram-se esfregaços sangüíneos das aves, diariamente, a partir do primeiro dia em que as aves do Grupo 1 e do Grupo 2 foram expostas aos carrapatos até o 25 dia após a exposição (DPE), para o acompanhamento da evolução da espiroquetemia. Foram observados 50 campos por esfregaço sanguíneo em microscópio óptico (Leitz Wetzalar, Dialux 20 EB) com objetiva de 100x. Quando uma lâmina se apresentava positiva, calculava-se o número médio por campo (Shommein \& Khogali 1974).

No $64^{\circ}$ dia de idade, três dias antes da exposição aos carrapatos, foram coletadas amostras de sangue de cada ave, por meio de venopunção basílica (veia alar), usando-se anticoagulante EDTA, na proporção de $50 \mu \mathrm{L}$ para $2,0-3,0 \mathrm{ml}$ de sangue. Este primeiro hemograma foi utilizado como valor padrão normal para controle dos grupos. Uma segunda amostra foi coletada três dias após a exposição (DPE) das aves dos Grupos 1 e 2 aos carrapatos infectados e livres de B. anserina, 
respectivamente (aves com 70 dias de idade); uma terceira amostragem em oito DPE (aves com 75 dias de idade); e uma última e quarta amostragem em dezoito DPE (aves com 85 dias de idade). Após as coletas, as amostras contidas nas seringas foram acondicionadas e transportadas em isopor contendo gelo reciclável e encaminhadas ao Laboratório de Patologia Clínica, do Instituto de Veterinária da UFRRJ, para serem analisadas.

As amostras de sangue foram transferidas para tubos de plástico, para serem realizadas as seguintes provas hematológicas: determinação do volume globular (VG) efetuado através do método do micro-hematócrito segundo metodologia descrita por Jain (1986); concentração de proteínas plasmáticas totais (PPT) (g/dl) e do fibrinogênio determinados por meio do método de refratometria (Coles 1984); concentração de hemoglobina, através do método de oxi-hemoglobina (Coles 1984); contagens de eritrócitos, leucócitos totais e trombócitos realizadas em hemocitômetro, utilizando-se a solução de Natt \& Herrick (1951). Por meio de fórmulas padronizadas foram calculados os seguintes índices de Wintrobe (1933): volume globular médio (VGM) e concentração de hemoglobina globular média (CHGM).

A contagem de leucócitos e plaquetas foi realizada na diluição de 1/20 e a contagem de eritrócitos na diluição de 1/ 200. Foram contados os leucócitos e plaquetas do quadrante $1 \mathrm{~mm}^{3}$ central ( 25 subdivisões do retículo melhorado da câmara de Neubauer) e; os eritrócitos foram contados neste mesmo quadrante em $1 / 5$ de $\mathrm{mm}^{3}$ (cinco subdivisões do retículo melhorado central da câmara de Neubauer). Os respectivos fatores de correção para as contagens totais de leucócitos e plaquetas e de eritrócitos foram o número de células contadas vezes 200 e 10.000, respectivamente; considerando-se área, altura da câmara e diluição.

A contagem diferencial leucocitária foi realizada por meio de esfregaços sangüíneos corados pelo Giemsa para determinação dos valores relativos e posteriormente dos valores absolutos de linfócitos, heterófilos, monócitos e basófilos.

Foram utilizados controles internos dentro do grupo experimental e do próprio indivíduo, os quais foram submetidos às mesmas condições experimentais.

O delineamento utilizado foi inteiramente casualizado em parcelas subdivididas, com três tratamentos na parcela e quatro avaliações em diferentes épocas nas subparcelas, com nove repetições por tratamento. Para análise quantitativa dos diferentes parâmetros estudados, foi utilizada a análise de variância (ANOVA) com grau de significância a 5\% $(p<0,05)$, utilizando o software R (Development Core Team 2005). Os gráficos foram construídos no programa computacional Sigma Plot $^{\circledR}$ (Charland 1995).

\section{RESULTADOS E DISCUSSÃO}

O exame dos esfregaços sangüíneos das aves do Grupo 1 revelou grande número de espiroquetas sendo observadas também manifestações clínicas, tais como penas arrepiadas, crista pálida, sonolência, inapetência, perda de peso e diarréia esverdeada. Os esfregaços sangüíneos das aves do Grupo 2 e do Grupo 3 mantiveram-se negativos durante todo o período experimental e não foram observadas alterações clínicas. Os valores obtidos nas análises hematológicas do Grupo 1, no oitavo DPE estão apresentados nos Quadros 1 e 2.

Os valores hematológicos dos Grupos 2 e 3 apresentaram-se próximos durante todo o experimento não diferindo significativamente na maior parte das análises efetuadas (Fig.1a-c). Esta diferença observada é inerente ao erro esperado na execução da técnica.

No pico de espiroquetemia ocorrido no oitavo DPE, os valores hematológicos do grupo 1 apresentaram decréscimo significativo em relação aos demais grupos. No $18^{\circ} \mathrm{DPE}$, estes valores apresentaram um aumento tendendo a se normalizarem, e a partir do $13^{\circ}$ DPE houve melhora clínica, as aves retornaram a se alimentar normalmente, e as espiroquetas não foram mais encontradas nos esfregaços.

Shommein \& Khogali (1974) relataram a ocorrência de marcante diminuição do número de eritrócitos e da concentração de hemoglobina no sangue de aves parasitadas por $B$. anserina. $O$ mesmo fenômeno foi observado no presente estudo.

Bandopadhyay \& Vegad (1983), relataram que a anemia apresentada no quadro clínico da borreliose aviária pode ser causada pela destruição de eritrócitos ou por diminuição da produção, que são os mesmos mecanismos que ocorrem em mamíferos. Segundo Hutyra et al. (1947), essa diminuição da produção de eritrócitos ocorre devido à multiplicação inicial das espiroquetas no fígado, baço e medula óssea e a causa da destruição se atribui, provavelmente à substâncias tóxicas.

Quadro 1. Variáveis observadas no hemograma de Gallus gallus domesticus. Grupo 1 [aves expostas a Argas (Persicargas) miniatus infectados com Borrelia anserina], Grupo 2 (aves expostas a A. miniatus livres de $B$. anserina) e Grupo 3 (aves não expostas aos carrapatos), oito dias pós-exposição aos carrapatos

\begin{tabular}{|c|c|c|c|c|c|c|c|c|c|}
\hline \multirow[t]{2}{*}{ Variáveis } & \multicolumn{3}{|c|}{ Grupo 1} & \multicolumn{3}{|c|}{ Grupo 2} & \multicolumn{3}{|c|}{ Grupo 3} \\
\hline & $\operatorname{lnf}{ }^{*}$ & Sup $^{\star *}$ & Média*** & $\operatorname{lnf}^{*}$ & Sup ${ }^{\star *}$ & Média ${ }^{* * *}$ & $\operatorname{lnf}^{*}$ & Sup $^{\star *}$ & Média $^{\star \star \star}$ \\
\hline Eritrócitos (x 106/IL) & 1,2 & 2,1 & $1,8 \pm 0,3$ a & 1,8 & 2,6 & $2,2 \pm 0,3 b$ & 1,8 & 3,7 & $2,3 \pm 0,6 \mathrm{~b}$ \\
\hline VG $(\%)$ & 20,0 & 31 & $26,0 \pm 3,4$ a & 29,0 & 40,0 & $31,0 \pm 3,5$ b & 26,0 & 37,0 & $29,0 \pm 3,4 \mathrm{~b}$ \\
\hline VGM (fl) & 126,32 & 166,67 & $145,29 \pm 15,6$ a & 119,23 & 161,11 & $144,77 \pm 12,7 a$ & 75,68 & 176,19 & $135,51 \pm 31,2 a$ \\
\hline CHGM (\%) & 23,21 & 30,83 & $26,87 \pm 2,6$ a & 24,50 & 29,67 & $28,03 \pm 1,5 \mathrm{a}$ & 22,70 & 32,59 & $29,06 \pm 3,1 \mathrm{a}$ \\
\hline Hemoglobina $(\mathrm{g} / \mathrm{dL})$ & 5,1 & 8,2 & $7,0 \pm 0,9$ a & 8,0 & 9,8 & $8,7 \pm 0,6$ b & 7,6 & 9,0 & $8,4 \pm 0,5$ b \\
\hline Trombócitos (x 103/iL) & 24,6 & 44,4 & $36,0 \pm 6,7 a$ & 40,2 & 62,8 & $48,6 \pm 5,9 b$ & 32,0 & 51,8 & $42,2 \pm 8,4 a, b$ \\
\hline PPT (g/dL) & 3,8 & 5,8 & $4,7 \pm 0,6$ a & 3,0 & 5,2 & $3,8 \pm 0,7 \mathrm{~b}$ & 3,2 & 4,0 & $3,7 \pm 0,3 \mathrm{~b}$ \\
\hline Fibrinogênio & 200 & 800 & $444 \pm 194,4 a$ & 200 & 600 & $356 \pm 166,7 \mathrm{a}$ & 200 & 600 & $333 \pm 141,4 a$ \\
\hline
\end{tabular}

* Limite inferior, ${ }^{* *}$ Limite superior, ${ }^{* * *}$ Valores de média \pm desvio padrão $(n=9)$.

Nas linhas, letras diferentes indicam diferença significativa $(p<0,05)$ entre médias. 
Quadro 2. Variáveis observadas no leucograma de Gallus gallus domesticus. Grupo 1 [aves expostas a Argas (Persicargas) miniatus infectados com Borrelia anserina], Grupo 2 [aves expostas a A. miniatus livres de $B$. anserina] e Grupo 3 [aves não expostas aos carrapatos], oito dias pós-exposição aos carrapatos

\begin{tabular}{|c|c|c|c|c|c|c|c|c|c|}
\hline \multirow[t]{2}{*}{ Variáveis } & \multicolumn{3}{|c|}{ Grupo 1} & \multicolumn{3}{|c|}{ Grupo 2} & \multicolumn{3}{|c|}{ Grupo 3} \\
\hline & $\operatorname{lnf}^{*}$ & Sup ${ }^{* *}$ & Média*** & $\operatorname{lnf}{ }^{*}$ & Sup ** & Média*** & $\operatorname{lnf}^{*}$ & Sup ${ }^{* *}$ & Média*** \\
\hline Leucócitos & 18,60 & 49,80 & $34,31 \pm 8,5 \mathrm{a}$ & 8,80 & 24,00 & $16,64 \pm 4,7 \mathrm{~b}$ & 14,00 & 33,00 & $22,16 \pm 6,2 b$ \\
\hline Linfócitos & 4,09 & 26,27 & $12,48 \pm 6,4 a$ & 5,81 & 12,42 & $9,33 \pm 2,2 \mathrm{a}$ & 5,04 & 17,88 & $11,15 \pm 4,3 a$ \\
\hline Heterófilos imaturos & 0,00 & 0,00 & $0,00 \pm 0,0 \mathrm{a}$ & 0,00 & 0,00 & $0,00 \pm 0,0 a$ & 0,00 & 0,00 & $0,00 \pm 0,0 \mathrm{a}$ \\
\hline Heterófilos maduros & 5,97 & 29,88 & $14,53 \pm 7,5$ a & 1,85 & 12,24 & $4,92 \pm 3,2 \mathrm{~b}$ & 2,12 & 13,5 & $6,79 \pm 3,5 \mathrm{~b}$ \\
\hline Monócitos & 2,95 & 11,02 & $7,22 \pm 2,7 \mathrm{a}$ & 0,50 & 5,28 & $2,36 \pm 1,5 b$ & 1,5 & 5,94 & $3,05 \pm 1,5 \mathrm{~b}$ \\
\hline Eosinófilos & 0,00 & 0,39 & $0,08 \pm 0,2 a$ & 0,00 & 0,22 & $0,04 \pm 0,1 \mathrm{a}$ & 0,00 & 0,25 & $0,06 \pm 0,1 \mathrm{a}$ \\
\hline Basófilos & 0,00 & 0,00 & $0,00 \pm 0,0 \mathrm{a}$ & 0,00 & 0,00 & $0,00 \pm 0,0 \mathrm{a}$ & 0,00 & 0,00 & $0,00 \pm 0,0 \mathrm{a}$ \\
\hline $\mathrm{H} / \mathrm{L}$ & 0,22 & 2,73 & $1,50 \pm 0,95 \mathrm{a}$ & 0,32 & 1,38 & $0,66 \pm 0,38 \mathrm{~b}$ & 0,26 & 1,89 & $0,57 \pm 0,51 \mathrm{~b}$ \\
\hline
\end{tabular}

* Limite inferior, ${ }^{* *}$ Limite superior, ${ }^{* * *}$ Valores de média \pm desvio padrão $(n=9)$.

Nas linhas, letras diferentes indicam diferença significativa $(p<0,05)$ entre médias.
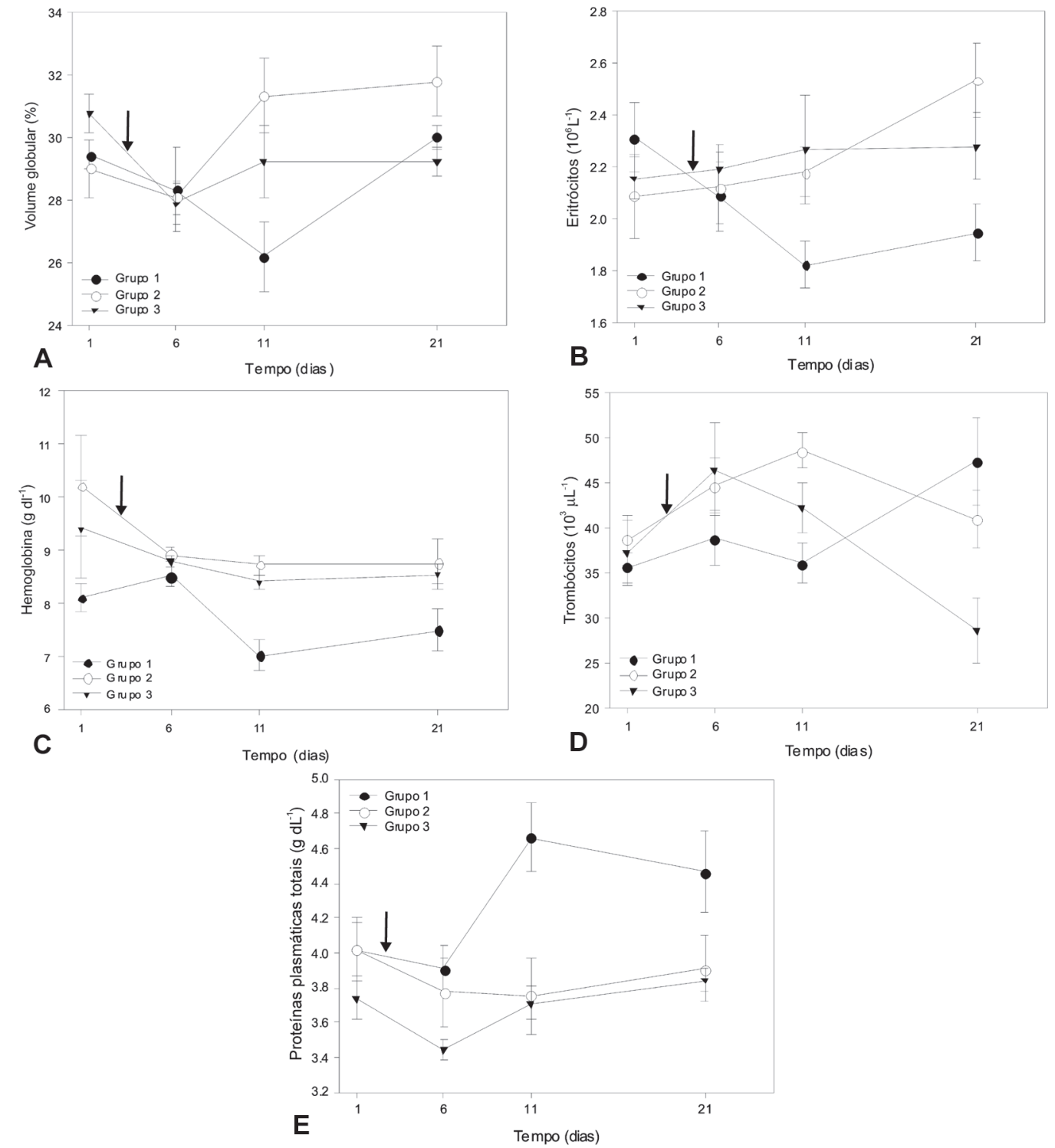

Fig.1. Alterações observadas no volume globular (A), contagem de eritrócitos (B), valores de concentração de hemoglobina (C), contagens de trombócitos $(\mathbf{D})$ e nas dosagens de proteínas plasmáticas totais $(\mathbf{E})$ de Gallus gallus domesticus. Grupo 1 (aves expostas a Argas (P.) miniatus infectados com Borrelia anserina), Grupo 2 (aves expostas a $A$. ( $P$.) miniatus livres de B. anserina) e Grupo 3 (aves não expostas aos carrapatos), 6, 11 e 21 dias após o primeiro hemograma. Barras verticais indicam o desvio padrão em referência às médias. A seta indica o momento da exposição dos Grupos 1 e 2 aos carrapatos. 

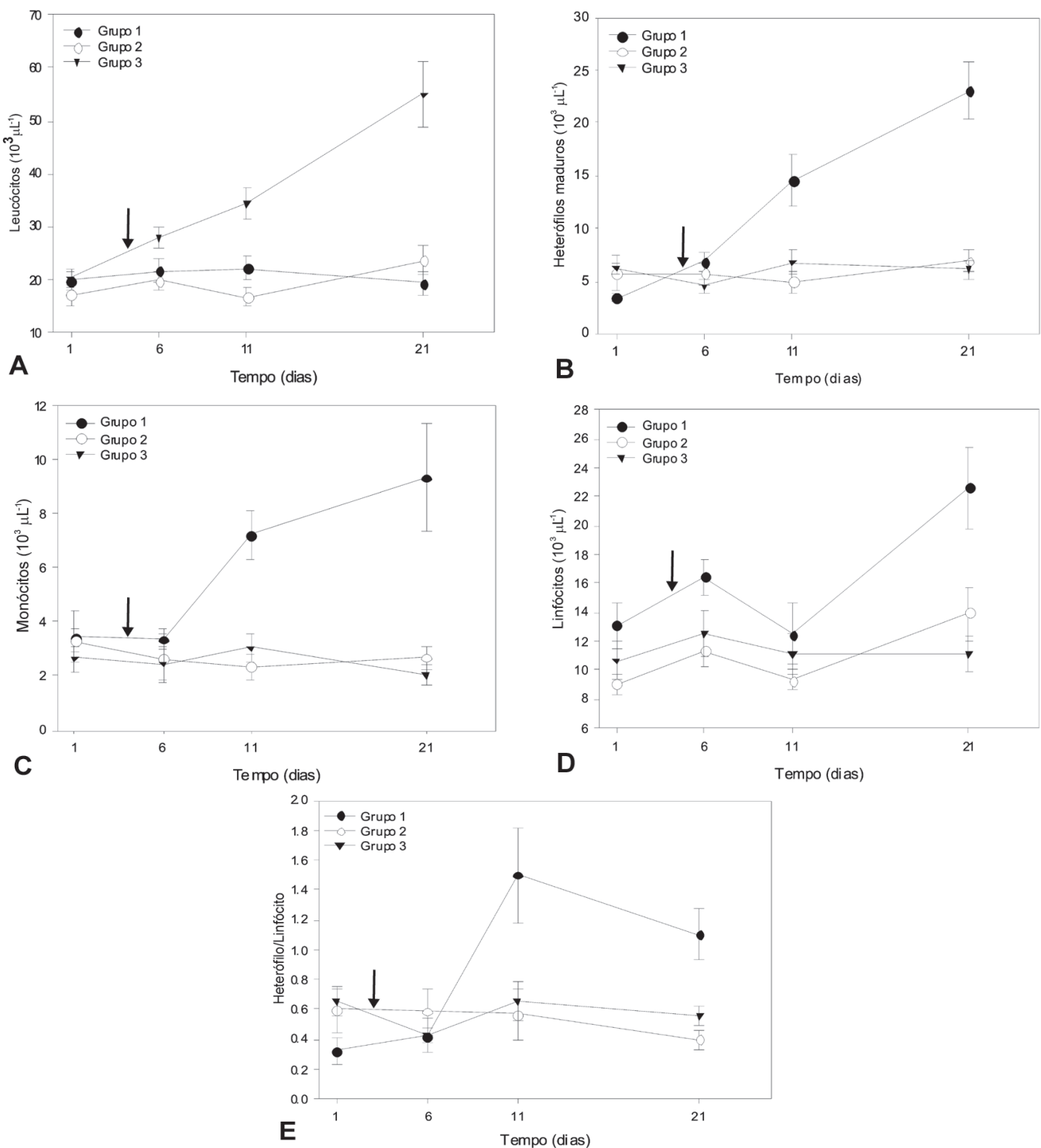

Fig.2. Alterações observadas nas contagens de leucócitos (A), heterófilos maduros (B), monócitos (C), linfócitos (D) e nas relações heterófilo/linfócito (E) de Gallus gallus domesticus. Grupo 1 (aves expostas a Argas (P.) miniatus infectados com Borrelia anserina), Grupo 2 (aves expostas a $A$. ( $P$.) miniatus livres de $B$. anserina) e Grupo 3 (aves não expostas aos carrapatos), 6,11 e 21 dias após o primeiro hemograma. Barras verticais indicam o desvio padrão em referência às médias. A seta indica o momento da exposição dos Grupos 1 e 2 aos carrapatos.

De acordo com os índices de Wintrobe (1933) analisados (VGM e CHGM), as aves do Grupo 1 apresentaram um quadro de anemia normocítica normocrômica.

No presente estudo foi observada, também, no Grupo 1, alteração na consistência do sangue, que se tornou aquosa a partir do $5^{\circ}$ DPE. Embora inespecífica, esta alteração fornece ao clínico evidências imediatas de anormalidade, neste caso, possivelmente, relacionada ao processo anêmico desenvolvido. Não foram encontrados registros deste fenômeno na literatura relacionado à infecção por $B$. anserina. Nos Grupos 2 e 3, a consistência sanguínea se manteve normal até o final do experimento.

A contagem de trombócitos (Fig.1d) diferiu significativamente entre os grupos. Essa oscilação foi mais evidente no Grupo 1, de 8-18 DPE, quando ocorreu aumento na produção de trombócitos acompanhado pelo VG e eritrócitos, caracterizando resposta medular. $\mathrm{O}$ aumento nos parâmetros hematológicos pode estar relacionado ao início da melhora clínica em decorrência da diminuição da espiroquetemia. Os Grupos 2 e 3, mesmo variando entre si, apresentaram uma tendência semelhante de diminuição.

Ocorreu um aumento significativo no valor de proteínas plasmáticas totais do Grupo 1 no hemograma do oitavo DPE (Fig.1e), em função da diarréia apresentada pelas aves, ocasionando perda de líquido plasmático e, consequentemente, hemoconcentração. A hiperproteinemia observada está associada à desidratação e à perda de peso durante o pico de espiroquetemia. Esta, prova- 
velmente, gerou resposta imune levando à hiperglobulinemia, a qual poderia ser confirmada através da realização de estudos para elucidar quais as frações protéicas gerais e específicas foram alteradas.

Leucocitose significativa foi observada no Grupo 1, no período de 8-18 DPE (Fig.2a), indicando uma resposta à infecção. Na contagem diferencial de leucócitos do Grupo 1 , os heterófilos predominaram nas fases iniciais do processo inflamatório (Fig.2b). Estas alterações acompanharam paralelamente as mudanças na leucometria global, já que, durante a inflamação aguda em galinhas, o desenvolvimento de leucocitose é devido à heterofilia (Jain 1986). Outro fator que favorece a leucocitose durante o pico de espiroquetemia é a desidratação que provoca hemoconcentração.

No experimento foi observada discreta monocitose em todos os grupos quando comparado aos valores de normalidade descritos por Jain (1986). Entretanto, como o grupo controle também apresentou monocitose, estes foram considerados dentro da normalidade para o grupo experimental estudado. A monocitose ocorrida de 8-18 DPE (Fig. 2c) sugere uma demanda maior de células do sistema mononuclear fagocitário (SMF) indiretamente em decorrência de esplenomegalia, conforme descrito por Boero (1967), Bier (1985), Cooper \& Bickford (1993); que pode estar associada à estimulação antigênica parasitária. Os achados de Bandopadhyay \& Vegad (1983) sugerem que a esplenomegalia é causada por uma reação inflamatória envolvendo uma resposta exagerada de macrófagos, hiperplasia dos órgãos do SMF, eritrofagocitose e hemossiderose.

No presente trabalho, a heterofilia e a monocitose tiveram correlações significativas e positivas com a leucocitose, enquanto a linfopenia ocorrida durante o período de patência (Fig.2d), teve correlação negativa, sem apresentar diferenças estatísticas significativas, provavelmente devido ao aumento relativo de heterófilos. Após este período ocorreu uma linfocitose.

$\mathrm{O}$ aumento da relação H/L no Grupo 1, demonstrado na Fig.2e, ocorreu como resultado de uma marcada heterofilia e uma pequena diminuição dos valores de linfócitos sem diferir do grupo controle. Em 18 DPE ocorreu uma diminuição nos valores médios da relação $\mathrm{H} / \mathrm{L}$ do Grupo 1 em decorrência da linfocitose, que segundo Jain (1986), possui uma correlação negativa com esta taxa. $\mathrm{O}$ aumento da relação $\mathrm{H} / \mathrm{L}$ teve uma correlação significativa e positiva com a leucocitose, heterofilia, monocitose e com o aumento das proteínas plasmáticas. Vale ressaltar que a desidratação ocorrida no período colabora com a hiperproteinemia.

O perfil do leucograma apresentado neste estudo corrobora com o descrito por Boero (1967).

\section{CONCLUSÃO}

A transmissão experimental de Borrelia anserina por Argus miniatus em Gallus gallus domesticus determinou alterações clínicas e hematológicas compatíveis com uma infecção bacteriana de média gravidade, evoluindo para auto-cura, nas condições estabelecidas neste trabalho.
Agradecimentos.- À CAPES, CNPq e FAPERJ pelo apoio financeiro; ao Prof. Dr. Romário Cerqueira Leite por ceder a cepa; à Dra ${ }^{a}$. Cristina Amorim, professora do Instituto de Zootecnia da UFRRJ, pela ajuda na fabricação das rações; e ao técnico Antônio Carlos Valentin Neves pelo auxílio no preparo das soluções do hemograma.

\section{REFERÊNCIAS}

Ataliba A.C., Resende J.S., Yoshinari N. \& Labruna M.B. 2007. Isolation and molecular characterization of a Brazilian strain of Borrelia anserina, the agent of fowl spirochaetosis. Res. Vet. Sci. 83(2):145-149.

Bandopadhyay A.C. \& Vegad J.L. 1983. Observations on the pathology of experimental avian spirochaetosis. Res. Vet. Sci. 35(2):138-144.

Bier O. 1985. Espiroquetose das galinhas, p.1118-1119. In: Bier O. (Ed.), Microbiologia e Imunologia. 24를 ed. Editora Melhoramentos, São Paulo.

Boero J.J. 1967. Parasitosis Animales. Editora Universidade de Buenos Aires. 498p.

Coles E.H. 1984. Patologia Clínica Veterinária. 3ª ed. Editora Manole, São Paulo. 566p.

Cooper G.L. \& Bickford A.A. 1993. Spirochetosis in California game chickens. Avian Dis. 37(4):1167-1171.

Charland M.B. 1995. SigmaPlot for Scientists. Wm. C. Brown Communications, 2460 Kerper Boulevard, Dubuque, lowa 52001.

DaMassa A.J. \& Adler H.E. 1979. Avian spirochetosis: natural transmission by Argas (Persicargas) sanchezi (Ixodoidea: Argasidae) and existence of different serologic and immunologic types of Borrelia anserina in the United States. Am. J. Vet. Res. 40(1):154-157.

Development Core Team. 2005. R: A language and environment for statistical Computing. R Foundation for Statistical Computing, Vienna, Austria. ISBN 3-900051- 07-0. URL http://www.R-project.org.

Dhawedkar R.G. \& Dhanesar N.S. 1983. Preservation of Borrelia anserina by liquid-nitrogen refrigeration. Indian J. Anim. Sci. 53(10): 1124-1127.

Garg R.R. \& Gautam O.P. 1971. Serological diagnosis of fowl Spirochetosis. Avian Dis. 15(1):1-6.

Hutyra F., Marek J. \& Manninger R. 1947. Espiroquetosis de las Aves de corral: Spirochaetosis avium, p.716-722. In: Hutyra F., Marek J. \& Manninger R. (Ed.), Patología y Terapéutica Especiales de los Animales Domésticos. Vol.1. Editorial Labor, Barcelona.

Jain N.C. 1986. Schalm's Veterinary Hematology. 4th ed. Lea and Febiger, Philadelphia. 1221p.

Labruna M.B., Resende J.S., Martins N.R.S. \& Jorge M.A. 1999. Criopreservação de uma amostra de espiroqueta em nitrogênio líquido. Arq. Bras. Med. Vet. Zootec. 51(6):551-553.

Magalhães F.E.P. 1979. Novos aspectos morfológicos, biológicos e tóxicos de Argas (Persicargas) miniatus Koch, 1844 (Ixodoidea, Argasidae) no Estado do Rio de Janeiro. Dissertação de Mestrado, Universidade Federal Rural do Rio de Janeiro, Seropédica, RJ. 95p.

Marchoux E. \& Salimbeni A. 1903. La spirillose des poules. Annales de I'Institut Pasteur, Lille, 17:569-580.

Natt M.P. \& Herrick C.A. 1951. A new blood diluent for counting the erythrocytes and leucocytes of the chicken. Poultry Sci. 31:735-738.

Sakharoff M.N. 1891. Spirochaeta anserina et la septicémie des oies. Annales de l'Institut Pasteur, Lille, 5:564-566.

Shommein A.M. \& Khogali A. 1974. Fowl spirochaetosis haematological and histopathological studies. Bull. Epizoot. Dis. Africa 22(3):255-261.

Souza P.C.A. 1998. Malaria aviária: parasitismo por Plasmodium (Novyella) juxtanucleare Versiani \& Gomes, $1941 \mathrm{em}$ Gallus gallus L. de criações rústicas, nas mesorregiões do estado do Rio de Janeiro e aspectos clínicos e patológicos de sua infecção experimental. Tese de Doutorado, UFRRJ, Seropédica, RJ. 137p.

Wintrobe M.M. 1933. Variations in the size and hemoglobin content of eritrocytes in the blood of various vertebrates. Folia Haematologica, Leipzig, 51:31. 